\title{
Capacitive Mode Methanol Sensing by ZnO Nanorods Based Devices
}

\author{
N. Banerjee, K. Dutta, H. Misra and P. Bhattacharyya
}

\begin{abstract}
Capacitive mode methanol sensing performance of $\mathrm{ZnO}$ hexagonal nanorods based MIS devices having diameters of 40-60 nm and lengths of 460-480 nm, is reported in this paper. $\mathrm{ZnO}$ nanorods were synthesized on $\mathrm{p}$-Si substrate by chemical bath deposition method (CBD) using $50 \mathrm{ml}$ aqueous solution of Zinc acetate dihydrate and HMT. The as deposited sensor with Pd catalytic contact in metal-insulator-metal (MIS) configuration offered $99 \%$ response magnitude (RM) in the temperature range of $(300-325){ }^{\circ} \mathrm{C}$ towards $700 \mathrm{ppm}$ methanol concentration. The response time (Rs:140s) and recovery time (Rc:110s) of the methanol sensor at $325^{\circ} \mathrm{C}$ were also obtained. The sensor was able to detect methanol even down to $10 \mathrm{ppm}$.
\end{abstract}

Index Terms-Capacitive sensor, $\mathrm{CBD}, \mathrm{ZnO}$ hexagonal nanorods, methanol sensing.

\section{INTRODUCTION}

Recent advances in nanomaterials provide the opportunity to dramatically increase the response of these materials, as their performance is directly related to exposed surface volume. Detection of toxic and flammable gases is a subject of growing significance in both domestic and industrial environments [1]. Various air pollutants coming from industrial plants, households or automobiles should be controlled in order to keep them below a safe level. This has motivated the researchers to develop various types of gas sensors based on different principles. The conductometric semiconducting metal oxide gas sensors currently constitute one of the most investigated groups of gas sensors. Metal-insulator-semiconductor (MIS) structure attracts the interests as its capacitance (based on surface space charge of semiconductor) is delicately influenced by effective voltage applied on metal electrode for detecting combustible, reducing, or oxidizing gases by conductive measurements [2] The gas sensors used noble metal electrode as a sensing material. The following oxides show a gas response in their conductivity: $\mathrm{Cr}_{2} \mathrm{O}_{3}, \mathrm{NiO}, \mathrm{CuO}, \mathrm{SrO}, \mathrm{ZnO}, \mathrm{TiO}_{2}, \mathrm{~V}_{2} \mathrm{O}_{3}$, $\mathrm{Fe}_{2} \mathrm{O}_{3}, \mathrm{GeO}_{2}, \mathrm{Nb}_{2} \mathrm{O}_{5}, \mathrm{MoO}_{3}, \mathrm{Ta}_{2} \mathrm{O}_{5}, \mathrm{La}_{2} \mathrm{O}_{3}, \mathrm{CeO}_{2}, \mathrm{Nd}_{2} \mathrm{O}_{3}[3]$ Capacitive-type sensors have good prospects given that the capacitor structure is so simple enabling miniaturization and achieving high reliability and low cost. In addition, amplification of capacitance is easily performed by oscillator

Manuscript received July, 2015; revised January 10, 2016. This work is supported financially in part by the CSIR, DST and AICTE Career Award for young Teachers, Govt. of India.

N. Banerjee, K. Dutta, and P.Bhattacharyya are with the Department of Electronics and Telecommunication Engineering, Indian Institute of Engineering Science \& Technology, Shibpur, India (Tel.: +919038370727; e-mail: nabaneeta2007@gmail.com) circuits and thus, capacitive type sensors enable sensitive detection. In addition, oscillator circuits consist of only a standard resistor and sensor capacitor. Thus, the signal treatment circuit is also very simple and low cost. Moreover, the key advantage of the capacitive-type sensor is its selective detection of the specific gas molecules. $\mathrm{ZnO}$ nanomaterials have been widely studied for high-technology applications ranging from photonic crystals to light-emitting diodes, photo detectors, photodiodes, and gas sensors [4]. A variety of $\mathrm{ZnO}$ nanostructures have been demonstrated, for example, nanowires, nanorods, nanotubes, nanobelts, and nanoflowers. Among these, $\mathrm{ZnO}$ nanorods are of particular interest due to their electrical and optical properties. Various chemical, electrochemical, and physical deposition techniques have created structures of oriented $\mathrm{ZnO}$ nanorod arrays so far. Methanol is one of the prime raw materials for large scale production of many chemical products and materials including colors, dice, drugs, perfumes, formaldehyde which are of immense use for domestic and industrial appliances. According to the occupational health regulation, the upper concentration limits are $200 \mathrm{ppm}$ average concentration for 8 hour exposure and $250 \mathrm{ppm}$ maximum concentration for short term exposure. Till date several researchers have reported on the $\mathrm{ZnO}$ nanorods based gas sensor. C.S. Prajapati et al. [5] reported on $\mathrm{ZnO}$ thin film based resistive methanol sensors by spray pyrolysis technique with high operating temperature $\left(300^{\circ} \mathrm{C}\right)$ and low dynamic range $(50-250 \mathrm{ppm})$. T. Ishihara $e t$ al. [6] reported capacitive type gas $\left(\mathrm{CO}_{2}\right.$ and $\left.\mathrm{NO}\right)$ sensors, using depletion layer formed at $\mathrm{p}$-n junction of oxide semiconductor in detail. Capacitive-type gas sensors combining silicon semiconductor and $\mathrm{NaNO}_{2}$-based solid electrolyte for $\mathrm{NO}_{2}$ detection in the concentration range of 20-500 ppb was investigated by C. Zamani et al. [7]. C. Malagu et al. [8] fabricated poly crystalline WO3 thick film gas sensors for AC measurement by using sol-gel non-aqueous synthesis.

In this paper, for ac measurement of the sensor the preparation of $\mathrm{ZnO}$ nanorods on $\mathrm{p}-\mathrm{Si}$ substrate by chemical bath deposition (CBD) technique is reported for the detection of methanol vapor with lower dynamic range of 10-700 ppm in the temperature range of $(150-325)^{\circ} \mathrm{C}$. The effect of catalytic metal electrode ( $\mathrm{Pd}-\mathrm{Ag})$ was investigated within that dynamic cycle at high temperature of $325^{\circ} \mathrm{C}$ with high response magnitude (99.2\%) in capacitive mode compared to another higher temperature $\left(300^{\circ} \mathrm{C}\right)$ with $98.85 \% \mathrm{RM}$.

\section{EXPERIMENTAL DETAILS}

The detail growth mechanism of $\mathrm{ZnO}$ nanorod is similar to that described in our earlier publications [9]-[11]. The 
hexagonal $\mathrm{ZnO}$ nanorods were formed on oxidized $\mathrm{p}-\mathrm{Si}$ $<100>$ substrate by CBD method on the sol gel [using Zinc acetate dihydrate $\left(\mathrm{Zn}\left(\mathrm{CH}_{3} \mathrm{COO}\right)_{2}, 2 \mathrm{H}_{2} \mathrm{O}\right.$, Merck, $\left.99.9 \%\right)$ and 2-propanol]. The p-Si substrate was annealed at $450^{\circ} \mathrm{C}$ for 1 hour before growing nanorods on the seed layer. One ohmic contact (Pd) was deposited by e-beam vacuum evaporation technique (chamber pressure $\sim 10^{-6} \mathrm{mbar}$ ) on top of the sensing layer of as deposited $\mathrm{ZnO}$ nanorods using $\mathrm{Al}$ metal mask and the other ohmic contact has been taken from the bottom of the substrate (metal $\mathrm{Si}$ ). The device dimension was $5 \mathrm{~mm} \times 5 \mathrm{~mm}$ having each electrode area of $1 \mathrm{~mm} \times 1 \mathrm{~mm}$, shown in Fig. 1. The device formed is, thus, a gas sensor which is fabricated into Si-based MIS capacitor with a $\mathrm{ZnO}$ dielectric layer and a Pd upper electrode.

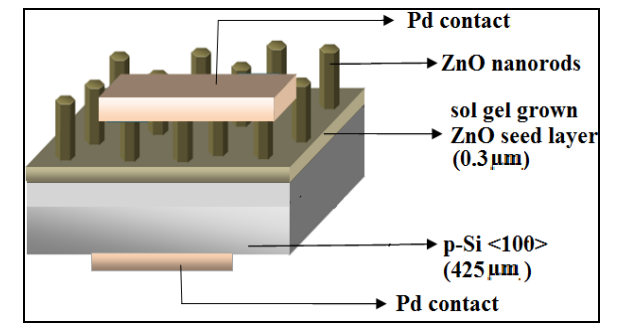

Fig. 1. Schematic diagram of as deposited MIS sensor.

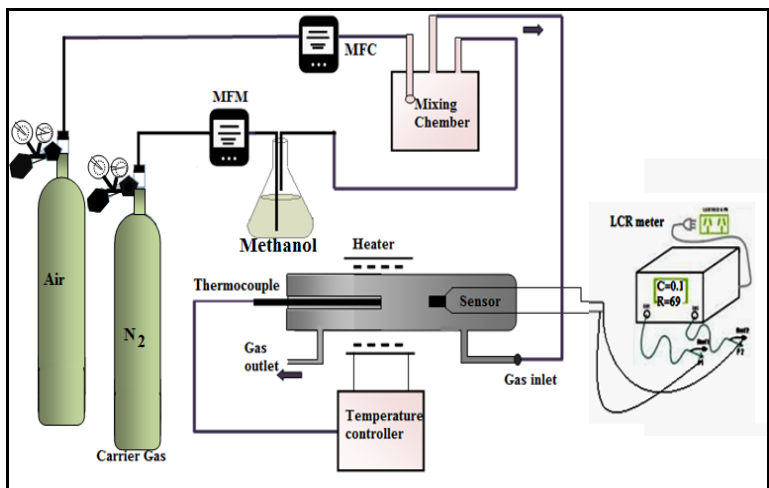

Fig. 2. Schematic diagram of gas sensor set-up.

In the gas sensing measurement set-up (Fig. 2), the sensor was placed in centre of a cylindrical chamber connected with a temperature controller with a temperature accuracy of $\pm 1^{\circ} \mathrm{C}$. During experiments, IOLAR grade $\mathrm{N}_{2}$ from a regulated gas cylinder was entered into methanol containing bubbler through a mass flow controller (MKS, USA). From this, saturated methanol vapours were collected into mixer, where it was diluted with known amount of air coming through another mass flow controller (MKS, USA)). The desired methanol concentrations were achieved through precisely controlling the carrier gas flow rate and diluents flow rate and were then subsequently introduced into the sensing chamber. Two connecting leads from the electrodes of the sensor were connected to an LCR meter for ac measurement of the sensor.

\section{RESULTS AND DISCUSSIONS}

\section{A. Structural Characterization}

The detail of structural XRD (using ULTIMA-III, $\mathrm{Cu} \mathrm{K \alpha}$ target, X-Ray Diffracto-meter, $\left.\lambda=1.54 \mathrm{~A}^{\circ}\right)$ and morphological characterizations like FESEM (Field Emission Scanning Electron Microscope, using Hitachi S-4800, $\mathrm{Cu} \mathrm{K \alpha}$ target, emitter voltage $=5 \mathrm{kV}$ and emitter current $=10 \mu \mathrm{A}$ ) characterizations was carried out.

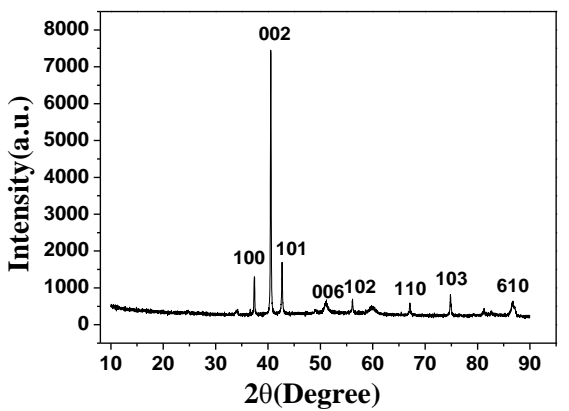

Fig. 3. XRD pattern of as deposited $\mathrm{ZnO}$ nanorods.

XRD (Fig. 3) confirmed strongest (002) preferential c-axis growth (at $40.65^{\circ}$ ). The other diffraction peaks positioned at $2 \theta$ values of $37.30,42.61,56.10,67.01,78.12$ can be indexed to the hexagonal wurtzite phase of $\mathrm{ZnO}$ (JCPDS card no: 01-080-0074) with crystallinity of (100), (101), (102), (110) and (200) planes respectively. However, there exist some impurity attributed weak peaks near $50.94^{\circ}$ with crystallinity of $\mathrm{Zn}(006)$ and $86.63^{\circ}$ of $\mathrm{O}(610)$.

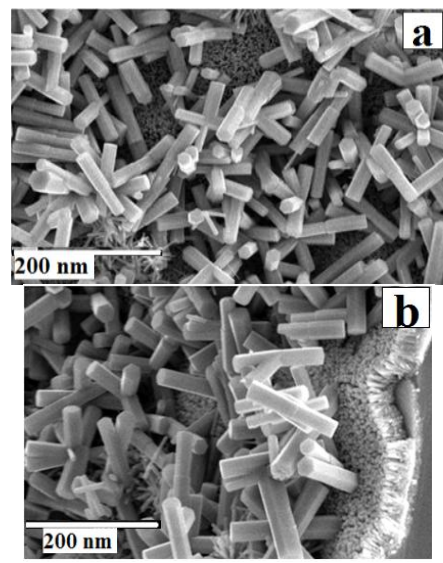

Fig. 4. FESEM images of (a) top view and (b) side view of as deposited $\mathrm{ZnO}$ nanorods.

FESEM image for as deposited $\mathrm{ZnO}$ nanorods based capacitive sensor is shown in Fig. 4(a) and (b). The micrographs explores that the hexagonal nanorods have diameter of about 40-60 nm with 460-480 nm length of one nanorod.

\section{B. Sensor Study}

Sol-gel derived CBD grown $\mathrm{ZnO}$ nanorods metal insulator semiconductor sensor is used for detection of different concentrations of (10-700ppm) methanol in the temperature range of (150-350) ${ }^{\circ} \mathrm{C}$. Transient response for methanol at optimum temperature $\left(325^{\circ} \mathrm{C}\right)$ and another higher temperature $\left(300^{\circ} \mathrm{C}\right)$ was investigated.

For finding out the optimum operating temperature of sensing, sensor capacitance was measured in presence of air and methanol vapor and the corresponding response magnitude was calculated as a function of temperature. Response Magnitude (RM) of the sensor was calculated by using the formula shown below [6]

$$
\operatorname{RM}(\%)=\frac{c_{\text {gas }}-c_{0}}{c_{0}} \times 100
$$


where $C_{\text {gas }}$ is the capacitance in the presence of methanol vapor and $C_{0}$ is the capacitance in presence of air.

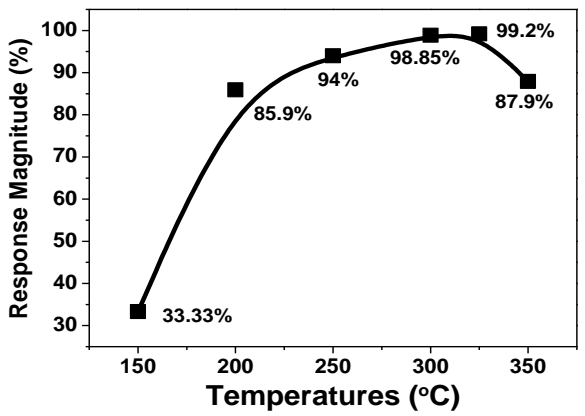

Fig. 5. RM (function of temperature) for $700 \mathrm{ppm}$ methanol concentration.

Fig. 5 represents sensor response magnitude as a function of temperatures for methanol concentration of $700 \mathrm{ppm}$. Monotonically increasing nature of the response magnitude was observed (at $700 \mathrm{ppm}$ ) with increasing temperature. Therefore, from operating temperature point of view, the optimum operating temperature (where response magnitude is the maximum) was noted at $325^{\circ} \mathrm{C}$. Below $150^{\circ} \mathrm{C}$, response was very slow (poor value) and above $325^{\circ} \mathrm{C}$, the sensor response became relatively unstable possibly due to the degradation of the sensing material.


Fig. 6. Transient response for different concentrations of methanol at (a) $325^{\circ} \mathrm{C}$ and (b) $300^{\circ} \mathrm{C}$.

Fig. 6(a) and (b) shows the transient curve for methanol at $325^{\circ} \mathrm{C}$ and $300^{\circ} \mathrm{C}$. Response below $150^{\circ} \mathrm{C}$ was not good, so neglected. From the transient response it can be observed that the capacitance of the sensor increases with the increase in methanol vapor concentration and the increase in capacitance is linear with the gas concentration. From Fig. 6 (a) and (b), it can be envisaged that the sensor offered $99.2 \% \mathrm{RM}$ at 700 ppm at optimum temperature $\left(325^{\circ} \mathrm{C}\right)$ while $98.85 \%$ at $300^{\circ} \mathrm{C}$. The sensor showed very low response as $35 \%$ at $325^{\circ} \mathrm{C}$ and $27.7 \%$ at $300^{\circ} \mathrm{C}$ at very low concentration of $10 \mathrm{ppm}$.

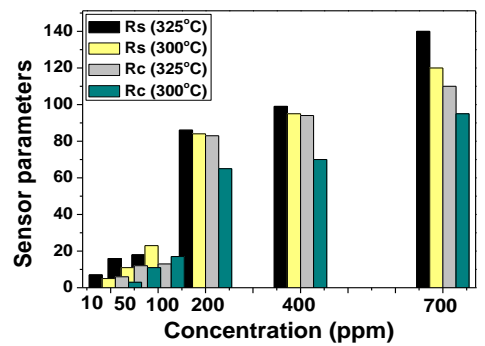

Fig. 7. Sensing parameters (response time, recovery time) at $325^{\circ} \mathrm{C}$ and $300^{\circ} \mathrm{C}$ at different methanol concentrations.

The response and recovery time of the sensors were calculated as time taken to reach $67 \%$ of the saturation value and the time needed to reach back to the original value. At $325^{\circ} \mathrm{C}$, the response $(\mathrm{Rs})$ and recovery $(\mathrm{Rc})$ time are obtained as $140 \mathrm{~s}, 110 \mathrm{~s}$ and at $300^{\circ} \mathrm{C}$ these are $120 \mathrm{~s}, 95 \mathrm{~s}$ respectively for $700 \mathrm{ppm}$ methanol vapor. So, it is observed from the bar diagram (Fig. 7) that Rs increases with increase of methanol concentrations and Rc decreases at low concentration. Table I represents the overall results for methanol sensor.

TABLE I: MEASURED SENSOR STUdy RESUlTS FOR THE OPTIMIZED OPERATING TEMPERATURES METHANOL SENSOR

\begin{tabular}{cccclcl} 
Concentrat & \multicolumn{3}{c}{$\mathbf{3 2 5}^{\mathbf{}} \mathbf{C}$} & \multicolumn{3}{c}{$\mathbf{3 0 0}^{\mathbf{C}}$} \\
\cline { 2 - 7 } i-ons (ppm) & $\mathbf{R M}$ & $\mathbf{R s}$ & $\mathbf{R c}$ & $\mathbf{R M}(\%)$ & $\mathbf{R s}$ & $\mathbf{R c}$ \\
\hline 700 & $99.2 \%$ & 140 & 110 & $98.85 \%$ & 120 & 95 \\
\hline 400 & $95 \%$ & 99 & 94 & $90.66 \%$ & 95 & 70 \\
\hline 200 & $90 \%$ & 86 & 83 & $89 \%$ & 84 & 65 \\
\hline 100 & $57.5 \%$ & 18 & 13 & $69 \%$ & 23 & 17 \\
\hline 50 & $51.6 \%$ & 16 & 12 & $43.4 \%$ & 11 & 11 \\
\hline 10 & $35 \%$ & 7 & 6 & $27.7 \%$ & 5 & 3 \\
\hline \hline
\end{tabular}

\section{SENSING MECHANISM}

A capacitor is a device that consists of two electrodes separated by an insulator. The electrical energy or charge is stored on these electrodes/plates. It is well known that, for a mixed dielectric system capacitance $(C)$ can be expressed as: $C=\varepsilon_{0} \varepsilon_{\text {reff }} A / d$, where $\varepsilon_{0}$ is the dielectric of vacuum, $\varepsilon_{\text {reff }}$ is the effective dielectric constant if single solid is considered (instead of layer wise dielectric), $\mathrm{A}$ is the electrode area and $\mathrm{d}$ is the thickness of dielectric layer. The dielectric may be air, mica, ceramic, fuel, or other suitable insulating material. Capacitive Gas Sensors measure the change in dielectric constant of films between the electrodes as a function of the gas concentration.

In present case, FESEM image (Fig. 3) revealed the presence of space between two adjacent $\mathrm{ZnO}$ nanorods. The ambient gas must have inclusion into these spaces. In turn the present case is considered as mixed dielectric system, rather single dielectric. For such reason, capacitance of the present device has been affected by ambient dielectric and dielectric of $\mathrm{ZnO}$ layer. Herein, ' $A$ ' and ' $t$ ' is the physical property of the device which is constant for a particular device (as shown in Fig. 1) and it can be observed that the $\mathrm{ZnO}$ nanorods between the Pd layer and Si substrate act as dielectric between two 
electrodes. So capacitances will be formed between the Pd layer and Si substrate which are in parallel. In this connection, the response of the MIS device towards methanol vapour can be explained as follows:

When the $\mathrm{ZnO}$ nanostructure is exposed to the methanol vapor, methanol is oxidized to form formaldehyde and subsequently formic acid and release electrons into the conduction band. As, methanol having higher dielectric constant than air, it increases the effective permittivity of the spaces in between $\mathrm{ZnO}$ nanorods assembly. Furthermore, depletion area of $\mathrm{ZnO}$ components is decreased in same time, as most of the literature in metal oxide based gas sensor field [6], [8]. Among the above mentioned two phenomena, the $2^{\text {nd }}$ phenomena only induce the effect of chemisorption and first phenomenon is a physical mixing occurrence. It can also be understood that, physical phenomenon should have dominant effect over chemisorption as only surface of $\mathrm{ZnO}$ is considered here (not bulk of $\mathrm{ZnO}$ ). Thus the dielectric constant of the spaces will be increased due to methanol exposure and hence, combining dominance, the $\varepsilon_{\text {reff }}$ will be increased. Such trend has been observed in sensor study.

\section{CONCLUSION}

The present work focus on the capacitive methanol sensing performance of $\mathrm{ZnO}$ nanorod based MIS device, grown by CBD method. In this endeavor, $\mathrm{Zn}\left(\mathrm{CH}_{3} \mathrm{COO}\right)_{2}, 2 \mathrm{H}_{2} \mathrm{O}$ and HMT were mixed in $50 \mathrm{ml}$ DI water to grow $\mathrm{ZnO}$ nanorods on p-Si substrate. After detailed structural characterizations through XRD and FESEM, the methanol sensing performance was also studied. The developed sensor showed quite promising results with a detection level $10 \mathrm{ppm}-700 \mathrm{ppm}$ with corresponding response magnitude of $35 \%-99.2 \%$ with (7s-140s) response time and (6s-110s) recovery time at an operating temperature of $325^{\circ} \mathrm{C}$. So, as the capacitance of the sensor increases with increase in the gas/vapor concentration, it can be concluded that the gas interaction changes the dielectric of the sensor.

\section{ACKNOWLEDGEMENT}

This work was supported by Indian National Science Academy (INSA). Authors thankfully acknowledge Prof. A. Basu Mallik, Dept. of Metallurgy \& Materials Engineering, IIEST, Shibpur, India for providing facility of XRD. One of the authors, N. Banerjee gratefully acknowledges TEQIP-II, IIEST, Shibpur, India and other author K. Dutta acknowledges COE, TEQIP-II, IIEST, Shibpur, India.

\section{REFERENCES}

[1] S. Nakata, K. Shimanoe, N. Miura, and N. Yamazoe, " $\mathrm{NO}_{2}$ sensing properties of FET devices attached with $\mathrm{NaNO}_{2}$-based binary auxiliary phase," Electrochemical Society Proceedings, vol. 18, pp. 414-423, 2001.

[2] V. G. Litovchenko, T. I. Gorbanyuk, A. A. Efremov, and A. A. Evtukh, "Effect of macrostructure and composition of the top metal electrode on properties of MIS gas sensors," Micro Electronics Reliability, vol. 40, pp. 821-824, 2000.
[3] G. Korotcenkov, "Metal oxides for solid-state gas sensors: What determines our choice," Material Science Enineering B, vol. 139, pp. 1-23, 2007.

[4] S. H. Yi, S. K. Choi, J. M. Jang, J. A. Kim, and W. G. Jung, "Low-temperature growth of $\mathrm{ZnO}$ nanorods by chemical bath deposition," 2007.

[5] C. S. Prajapati and P. P. Sahay, "Alcohol-sensing characteristics of spray deposited $\mathrm{ZnO}$ nano-particle thin films," Sensors and Actuators $B$, vol. 160, pp. 1043-1049, 2011.

[6] T. Ishihara and S. Matsubara, "Capacitive type gas sensors," Journal of Electroceramics, vol. 2, pp. 215-228, 1998.

[7] C. Zamani, K. Shimanoe, and N. Yamazoe, "A new capacitive-type $\mathrm{NO}_{2}$ gas sensor combining an MIS with a solid electrolyte," Sensors and Actuators B, vol. 109, pp. 216-220, 2005

[8] C. Malagu, M. C. Carotta, S. Gherardi, V. Guidi, B. Vendemiati, and G. Martinelli, "AC measurements and modeling of $\mathrm{WO}_{3}$ thick film gas sensors," Sensors and Actuators B, vol. 108, pp. 70-74, 2005.

[9] N. Banerjee, C. K. Sarkar, and P. Bhattacharyya, "Development of an Ethanol Sensor based on CBD Grown ZnO Nanorods," Solid State Electronics (ELSEVIER), vol. 87, pp. 43-50, 2013.

[10] N. Banerjee, B. Bhowmik, S. Roy, C. K. Sarkar, and P. Bhattacharyya, "Anomalous recovery characteristics of Pd modified $\mathrm{ZnO}$ nanorod based acetone sensor," Journal of Nanoscience \& Nanotechnology, vol. 13, pp. 6826-6834, 2013.

[11] N. Banerjee, S. Roy, C. K. Sarkar, and P. Bhattacharyya, "Butanone sensing characteristics, mechanism and equivalent circuit model of $\mathrm{Pd}$ decorated $\mathrm{ZnO}$ nanorod based resistive sensors," Sensor Letters, vol. 12, pp. 89-96, 2014.

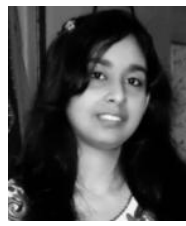

N. Banerjee received her M.Tech degree in instrumentation and control engineering from the Department of Applied Physics, University of Calcutta, India. She is presently pursuing the $\mathrm{PhD}$ degree from the Indian Institute of Engineering Science and Technology at Shibpur, Howrah, India. Her present research interest is $\mathrm{ZnO}$ based volatile organic compound (VOC) sensors.

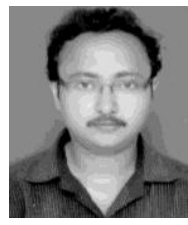

K. Dutta received the M.Tech. degree in radio physics and electronics from the University of Calcutta, Kolkata India. He is currently pursuing the $\mathrm{Ph} . \mathrm{D}$. degree at the Indian Institute of Engineering Science and Technology at Shibpur, Howrah, India. His present research interest is $\mathrm{TiO}_{2}$-based VOC sensors.

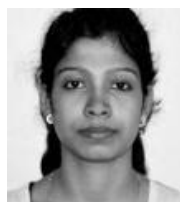

H. Misra has been awarded her B.Tech degree in electronics and telecommunication engineering from University of Guwahati, Guwahati, India. She received her M.Tech. degree from Indian Institute of Engineering Science and Technology at Shibpur, Howrah, India.

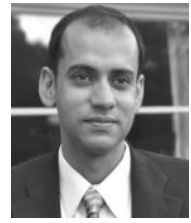

Partha Bhattacharyya received his M.E. degree in electron devices from Jadavpur University, India in 2002 and 2004 respectively. He received his $\mathrm{PhD}$ degree on 'MEMS based gas sensor and its integration with CMOS circuits' from the same University in 2008. Presently, he is an assistant professor in the Department of Electronics and Telecommunication Engineering, IIEST, India. He was a visiting scientist at Institute of Micro- and Nanomaterials, Ulm University, Germany in 2015 for his post doctoral research. His current research interests include nanomaterial based sensors, MEMS-based chemical sensors and its CMOS Integration. He has published about hundred and ten research articles in the reputed journals and conferences. He received the Young Engineer's Award from the Institution of Engineers, India, in 2010, Career Award for Young Teachers (CAYT) 2011-12 from All India Council for Technical Education (AICTE), 'Young Engineer Award 2012' from INAE and 'Young Scientist Award 2012' from INSA for his teaching and research contributions. 